\title{
UPAYA PENINGKATAN KECERDASAN EMOSI SISWA SEKOLAH DASAR MELALUI PENDIDIKAN JASMANI HARMONI
}

\author{
Eunike R. Rustiana \\ Universitas Negeri Semarang \\ email: eunike_rustiana@yahoo.com
}

\begin{abstract}
Abstrak: Penelitian ini bertujuan untuk mendapatkan bukti bahwa Pendidikan Jasmani Harmoni efektif meningkatkan kecerdasan emosi siswa SD. Penelitian ini berdasar pada teori kognitif sosial dari Bandura. Materi Penjas Harmoni terdiri atas permainan, olahraga, dan tarian masal (tari Saman). Subjek penelitian adalah siswa kelas V enam SDN yang berbeda, dengan tiga kelas sebagai kelompok intervensi yang diajar penjas Harmoni, dan tiga kelas sebagai kelompok kontrol yang diajar penjas reguler. Perlakuan berlangsung selama 14 kali pertemuan. Kecerdasan emosi diukur sebelum dan sesudah perlakuan dengan Skala Perasaan modifikasi dari Bar-On EQ inventory. Hasil penelitian menunjukkan nbahwa Penjas Harmoni efektif meningkatkan kecerdasan emosi siswa SD, yaitu kecakapan intrapersonal, interpersonal, penyesuaian diri, pengelolaan stres, dan sikap positif. Tidak ada pengaruh jenis kelamin, namun ada pengaruh bersama antara tingkat akreditasi sekolah dan jenis perlakuan terhadap peningkatan kecerdasan emosi. Penjas Harmoni disarankan untuk dipakai guruguru penjas SD di Semarang guna melengkapi KTSP 2006.
\end{abstract}

Kata Kunci: Pendidikan Jasmani Harmoni, kecerdasan emosi

\section{EFFORTS TO INCREASE THE EMOTIONAL INTELLIGENCE OF PRIMARY SCHOOL STUDENTS THROUGH HARMONY PHYSICAL EDUCATION}

\begin{abstract}
This study is aimed to ascertain the effectiveness of Harmony Physical Education (HPE) program to increase primary school students' emotional intelligence (EI). This study is based on Bandura's social cognitive theory, The material of HPE is consist of games, sports, and group dance(Saman Dance). The subjects of the study were fifth grade students from different Public Elementary Schools. They were randomly assigned into control group (three classrooms) who received regular PE program, and intervention group (another three classrooms) who received HPE program. The treatment was conducted in 14 weeks. Emotional intelligence was assessed before and after the treatment using Emotional Scale that was modified from Bar-On EQ inventory. The results show that HPE Program is effective in increasing primary school students' Emotional Intelegency which consists of intrapersonal, interpersonal, self adjustment, stress management, and positive attitudes. There were no gender role, but there is a relation between school acreditation level and the treatment used towards the improvement of emotional intelegency. Harmony Physical Education is recommended to be used by teachers in semarang as a supplement for KTSP 2006
\end{abstract}

Keywords: harmony physical education, emotional intelligence

\section{PENDAHULUAN}

Upaya pengembangan model pendidikan sebagian besar ditujukan untuk pengembangan intelektual saja. Akibatnya, terjadilah kesenjangan antara berkembangnya kecerdasan intelektual dengan kecerdasan emosi, sehingga muncullah berbagai perilaku negatif para siswa (Poerwanti, 2005). Ada siswa yang menganiaya teman, dan juga ada yang bunuh diri (Kompas, 2006). Di samping itu masih banyak lagi contoh-contoh perbuatan negatif yang dapat diamati pada kehidupan sehari-hari, misalnya pelanggaran lalu-lintas di lampu merah dan gerakan-gerakan demonstrasi yang merusak kantor-kantor atau bangunan milik pemerintah.

Menurut hasil penelitian Petrides dan Sangareau (2006), rendahnya nilai kecerdasan emosi berkorelasi dengan perilaku negatif. Kecuali itu Smith dan Walden (Ulutas \& Omeroglu, 2007) juga menemukan bahwa anak 
yang dinyatakan mempunyai perilaku buruk menunjukkan pemahaman emosi yang buruk. Seseorang yang cerdas emosi mampu menghadapi tantangan hidup dan mengontrol emosi lebih baik. Dari hasil-hasil penelitian ini dapat disimpulkan bahwa agar tidak membuat perilaku-perilaku negatif, kecerdasan emosi anak harus tinggi, atau anak harus dibuat cerdas emosi. Salovey dan Mayer (Lopez et al, 2003) menyatakan bahwa kecerdasan emosi dapat di capai atau ditingkatkan melalui pembelajaran dan pengalaman. Dengan demikian untuk menghindari kemungkinan terjadinya perilaku negatif, perlu ada usaha pengembangan kecerdasan emosi sejak masa kanak-kanak atau paling tidak sejak usia SD (Ibrahim, 2001). Dinyatakan oleh Bucher dan Thaxton (1979) serta Freud (Shapiro, 1997) bahwa bermain adalah pekerjaan atau dunia anak. Penjas mengandung suasana bermain (Lutan, 2004). Dengan demikian penjas mempunyai peluang untuk dimanfaatkan sebagai cara untuk meningkatkan atau mengembangkan kecerdasan emosi anak atau siswa SD.

Dalam Kurikulum 2006 atau Kurikulum Tingkat Satuan Pendidikan (KTSP), mata pelajaran Pendidikan Jasmani telah berubah nama menjadi Pendidikan Jasmani, Olahraga dan Kesehatan (Penjasorkes), standar kompetensi dan kompetensi dasar masih tetap digunakan sebagai acuan dalam menyusun program pembelajaran. Sekolah-sekolah semakin diberi kebebasan untuk membuat silabi sesuai dengan situasi dan kondisi setempat. Kebijakan ini sebenarnya amat bermanfaat bagi para guru, yaitu untuk memacu kreativitas guru-guru tersebut, termasuk guru penjas, dalam menyusun materi pelajaran penjasorkes, agar menjadi lebih menarik bagi para siswa, sehingga tujuan penjasorkes dapat tercapai seluruhnya, termasuk pengembangan aspek sosial psikologis. Namun tidak semua guru penjas di SD mampu atau sempat mengembangkan materi pembelajaran penjasorkes secara maksimal. Hal ini disebabkan beberapa guru penjas bukan berasal dari pendidikan olahraga, dan harus merangkap memberikan mata pelajaran lain.

Materi Penjas Harmoni yang diusulkan ini ingin membantu memberi masukan bagi guru-guru penjas SD dalam menyusun rencana pembelajaran, di samping menawarkan cara mengembangkan kecerdasan emosi siswa SD. Materi Penjas Harmoni dicoba disusun dengan mengacu pada faktor-faktor kecerdasan emosi yang perlu dikembangkan melalui olahraga, permainan, dan tarian masal, dalam hal ini tari Saman, untuk mewakili aktivitas ritmik.

Masalah dalam penelitian ini adalah, apakah materi Pendidikan Jasmani Harmoni efektif dalam meningkatkan kecerdasan emosi siswa Sekolah Dasar? Penelitian ini bertujuan untuk menguji secara empirik efektivitas Pendidikan Jasmani Harmoni pada peningkatan kecerdasan emosi siswa SD.

Secara umum hasil penelitian ini, diharapkan dapat dijadikan alternatif cara pengembangan kecerdasan emosi siswa SD melalui pendidikan jasmani.

Secara lebih rinci hasil penelitian ini diharapkan dapat memberikan sumbangan-sumbangan yaitu: bagi guru-guru penjas SD materi Pendidikan Jasmani Harmoni dapat dimanfaatkan sebagai masukan dalam menyusun materi pembelajaran penjasorkes. Bagi perkembangan ilmu, diharapkan hasil penelitian ini dapat menambah fakta ilmiah tentang hubungan saling pengaruh antara jiwa dan raga. Penelitian-penelitian di bidang psikologi olahraga telah menggali pengaruh aspek psikologis pada kegiatan olahraga. Penelitian ini justru menggali sebaliknya, yaitu memanfaatkan kegiatan pendidikan jasmani dan olahraga untuk mengembangkan kecakapan psikologis, dalam hal ini kecerdasan emosi. Bagi pembangunan negara hasil penelitian ini diharapkan dapat memberi sumbangan berupa salah satu cara untuk meningkatkan kecerdasan emosi anak, melalui pendidikan jasmani.

Pada tahun 1990 Mayer dan Salovey (Kelly et al., 2004) menulis bahwa kecerdasan emosi adalah suatu tipe inteligensi sosial yang melibatkan kemampuan memantau emosi sendiri dan emosi orang lain, membedakannya, dan menggunakan informasi ini untuk mengarahkan pikiran dan tindakan. Salovey dan Mayer (Lopez et al., 2003) menyatakan bahwa kecerdasan emosi berpusat pada kemampuan emosi 
yang dapat dicapai melalui pembelajaran dan pengalaman. Kemudian Reuven Bar On (Hein, 2005) menyatakan bahwa kecerdasan emosi atau Emotional Intelligence (E.I) adalah susunan kecakapan non kognitif, kompetensi dan ketrampilan yang mempengaruhi kemampuan seseorang untuk berhasil dalam mengatasi tuntutan dan tekanan lingkungan..

Kecerdasan Emosi pada penelitian ini mengacu pada definisi dari Bar-On (2006) yang menjabarkan kecerdasan emosi ke dalam lima komponen pokok, yaitu komponen intrapersonal, interpersonal, penyesuaian diri, manajemen stres, dan general mood. Masing-masing komponen terdiri dari beberapa kemampuan sebagai berikut. Komponen Intrapersonal, meliputi kesadaran emosi, asertivitas, penghargaan diri, aktualisasi diri, dan kemandirian. Komponen Interpersonal meliputi empati ,tanggung jawab sosial, dan hubungan interpersonal. Komponen Penyesuaian Diri mencakup uji realita, fleksibilitas, dan pemecahan masalah. Komponen Manajemen Stres mencakup toleransi stres, dan kontrol impuls. Komponen General Mood mencakup optimisme dan Happiness.

Kecerdasan emosi berkembang sejak bayi lahir (Ulutas dan Omeroglu ,2007). Kemudian terus berkembang sejalan dengan perkembangan otak manusia, yang dibentuk oleh pengalaman, terutama pengalaman yang terjadi pada masa kanak-kanak awal. Menurut Goleman (2001), sampai kira-kira usia enam belas sampai delapan belas tahun, masih terjadi perkembangan otak bagian emosi yang cukup cepat. Pada masa dewasa, perkembangan otak masih berlangsung, namun tidak sepesat yang terjadi pada masa kanak-kanak dan masa remaja.

Hasil penelitian Bar-On (Goleman, 2001) menunjukkan bahwa peningkatan kecerdasan emosi pada orang dewasa perlahan-lahan namun konstan, dan puncak perkembangan kecerdasan emosi dalam kehidupan yang normal terjadi pada waktu manusia berusia empat puluhan. Ini disebut tahap kematangan.

Perkembangan kecerdasan emosi dipengaruhi oleh beberapa faktor seperti berikut. Temperamen (Kagan dalam Shapiro, 2003), keluarga (Gottman \& DeClaire, 1998), teman sebaya (Asher dalam Salovey \& Sluyter, 1997), sekolah (Salovey \& Sluyter, 1997), seni (Mandler dalam Strongman, 2003), media cetak dan elektronik (Gottman \& DeClaire, 1998), jenis kelamin (Petrides \& Sangareau 2006)) juga pendidikan kusus (Ulutas \& Omeroglu 2007).

Dalam penelitian ini program pendidikan khusus yang dimaksud adalah pembelajaran Penjas Harmoni. Penelitian ini menggunakan alat ukur kecerdasan emosi yang disebut Skala Perasaan. Skala ini dimodifikasi dari Bar-On EQ inventory for youth.

Dalam Kurikulum Tingkat Satuan Pendidikan KTSP (Mahendra dkk, 2006) dinyatakan bahwa Penjasorkes merupakan bagian integral dari pendidikan secara keseluruhan, bertujuan untuk mengembangkan aspek kebugaran jasmani, ketrampilan gerak, ketrampilan berfikir kritis, ketrampilan sosial, penalaran, stabilitas emosional, tindakan moral, aspek pola hidup sehat, dan pengenalan lingkungan bersih melalui aktivitas jasmani, olahraga dan kesehatan terpilih yang direncanakan secara sistematis dalam rangka mencapai tujuan pendidikan nasional.

Siswa SD adalah anak yang berusia antara 6 atau 7 tahun sampai 12 tahun atau 13 tahun. Para ahli psikologi menyebut usia ini sebagai usia berkelompok atau usia penyesuaian diri (Hurlock, 1999). Pada masa ini perhatian pokok anak adalah dukungan dari teman sebaya dan keanggotaan dalam kelompok, maka anak berusaha untuk menyesuaikan diri dengan teman-teman sebayanya. Guru, khususnya guru penjas dapat memanfaatkan sifat perkembangan ini untuk menanamkan kerjasama antar teman dan perilaku menghargai teman.

Melalui pengalaman gerak, siswa bisa mendapatkan perasaan-perasaan diakui, memiliki dan keberhasilan. Di samping itu sifat-sifat sosial seperti kejujuran, sportivitas, dan dapat dipercaya, yang mendukung kepribadian yang diinginkan secara sosial dapat dikembangkan.

Materi pembelajaran Penjas Harmoni ingin memperkaya Kurikulum Tingkat Satuan Pendidikan 2006 dengan cara merangkai permainan-permainan atau aktivitas-aktivitas fisik yang dianggap dapat dimanfaatkan untuk me- 
latih kemampuan-kemampuan psikologis yang tercakup di dalam kecerdasan emosi menurut konsep Bar-On. Materi atau kegiatan dari Penjas Harmoni selama 14 kali pertemuan pada semester I kelas V yaitu, Lari Berantai, melatih otot kaki, juga melatih kebersamaan atau kerjasama. Pertahankan Bola melatih otot kaki dan lengan, serta melatih asertivitas. Pantomim melatih otot wajah dan kesadaran ataupun ekspresi emosi.Sepak target meltih daya ledak penghargaan diri. Perahu Dayung melatih kekuatan dan koordinasi lengan dan kaki, juga kerjasama dan pengendalian diri. Mendengar aktif melatih penenangan, konsentrasi, dan empati. Ikuti Pemimpin melatih otot kaki, leher, dan lengan, juga aktualisasi diri dan kemandirian. Cerita Pendek Sekali melatih penenangan, juga uji realita. Rebut Bendera melatih koordinasi mata, kaki, lengan, juga tanggung jawab sosial. Tekateki melatih penenangan dan pemecahan masalah. Ping pong pik, melatih penenangan dan optimisme. Temukan Pemimpin melatih keluwesan gerak dan kecepatan berpikir. Titian Bambu melatih keseimbangan tubuh dan toleransi stres. Bola Panas, melatih lari, lompat, lempar, serta kerjasama dan kontrol impuls. Bermain Peran melatih empati. Tari Saman melatih otot seluruh tubuh dan daya tahan, juga keselarasan, kontrol impuls, dan kegembiraan.

Peningkatan kecerdasan emosi merupakan hasil psikologis yang diinginkan dari pembelajaran pendidikan jasmani. Menurut Ommundsen dan Bar-Eli (1999) tidak ada bukti yang menunjukkan hubungan langsun antara pelajaran pendidikan jasmani dengan hasil-hasil yang bersifat psikologis. Hubungan tersebut dapat dijelaskan melalui pendekatan kognitif sosial dari Bandura (2002). Pendekatan kognitif sosial berfokus pada persepsi dan kognisi siswa dalam kelas penjas dan faktor-faktor kontekstual/situasional yang mempengaruhinya.Riset kognitif sosial tentang motivasi dan belajar telah menunjukkan dengan jelas bahwa pikiran atau kognisi siswa pada gilirannya mempengaruhi afeksi, perilaku motivasional, dan penguasaan ketrampilan siswa dalam pendidikan jasmani (Lee et al, 1992).
Pendidikan Jasmani Harmoni diajukan dalam penelitian ini, dengan harapan agar materi penjas ini lebih berhasil menjangkau wilayah pengembangan afektif, sementara tetap memelihara keseimbangan dengan 3 wilayah pengembangan lainnya. Nama Harmoni dipilih karena mempunyai arti selaras atau seimbang. Pendidikan Jasmani Harmoni dapat dimasukkan ke dalam kelompok pendekatan pembelajaran terpadu, karena berusaha mengembangkan aspek intelektual, sosio-emosional, dan fisik pada waktu yang bersamaan.

Melalui proses pembelajaran terpadu, menurut Nopembri (2004) anak dilatih untuk bekerjasama, berekreasi, dan berkolaborasi dengan teman sejawatnya ataupun guru dalam memecahkan masalah-masalah yang dihadapi. Melalui kerjasama atau berhubungan dengan teman sebaya, siswa merasa terdukung dalam belajarnya (Azzarito dan Ennis, 2003). Materimateri kegiatan diambil dari buku Fair Play For Kids (Binder, 1995), dan buku Mengajarkan Emotional Intelligence Pada Anak (Shapiro, 2003) yang kemudian dimodifikasi. Pada pembelajaran ini ada materi yang tidak menggunakan latihan gerak sehingga ditempatkan pada saat selesai olahraga menjelang ganti pakaian. Misalnya pada pantomim, mendengar aktif, cerita pendek sekali, dan teka-teki.

Dalam materi pembelajaran Penjas Harmoni kecuali permainan-permainan peneliti juga memasukkan Tari Saman yang berasal dari Aceh pedalaman, yaitu daerah Gayo Alas, yang juga disebut Daerah Saman. Dalam Tari Saman gerakan mengangguk, menggeleng, melatih otot leher, gerakan membungkuk dan tegak melatih otot punggung, gerakan mengayun lengan ke belakang, ata, ke depan menyilang melatih otot persendian lengan dan gerakan duduk, berlutut tegak dan membungkuk melatih otot tungkai (Lawrence \& Hope, 2007).

Selain itu, juga mengembangkan kerjasama, pengendalian diri, dan kegembiraan (Hidayat, 2005). Dalam KTSP 2006 guru diberi keleluasaan memilih materi sesuai situasi dan kondisi setempat. Pada penelitian ini, yang mengambil tempat di Jawa Tengah, seharusnya peneliti memilih tari atau permainan misalnya 
soyang-soyang, cublak-cublak suweng, atau permainan Jawa Tengah yang lain. Namun tari Saman dipandang mempunyai nilai gerak fisik yang lebih kaya, lebih dapat mewakili aktivitas ritmik, karena nilai gerak fisiknya sama dengan senam irama, di samping juga mempunyai banyak muatan psikologis.Tari Saman dalam penelitian ini berfungsi sebagai media pendidikan, maka dapat dimasukkan dalam tari pendidikan (Ina, 2002). Tari pendidikan, dikatakan oleh Laban (Triana, 2005), juga Hidayat (2005), menekankan pembelajaran, bukan berorientasi pada hasil pertunjukan yang mengandung nilai seni tinggi. Dengan demikian dalam konteks ini siswa tidak dituntut untuk menari dengan indah, tetapi yang dipentingkan adalah, siswa belajar untuk berusaha kompak dengan teman.

Hasil-hasil psikologis dari pendidikan jasmani dipengaruhi oleh saling pengaruh (interplay) antara faktor-faktor kognitif individu dan karakteristik situasional. Pendekatan kognitif sosial berfokus pada persepsi dan kognisi siswa dalam kelas penjas dan faktor-faktor kontekstual atau situasional yang mempengaruhinya. Penjas saja tidak dengan sendirinya dapat menghasilkan seperti yang diinginkan (Crum, 2003), misalnya seperti yang termuat dalam tujuan dari KTSP 2006. Bila menginginkan pengembangan interaksi sosial, kemampuan berpikir logis, atau ketrampilan psikososial yang lain, materi pembelajaran penjas haruslah disusun sesuai dengan hasil yang ingin dicapai (Crum, 2003). Penjas Harmoni mencoba meramu materi yang berisi bagian-bagian gerakan olahraga, permainan-permainan, dan tarian masal (tari Saman) yang diperkirakan dapat dimanfaatkan untuk mengembangkan kecerdasan emosi. Kecerdasan emosi yang dimaksud adalah kumpulan dari kecakapan-kecakapan kerjasama, asertivitas, kesadaran emosi, penghargaan diri, pengendalian diri atau kontrol impuls, empati, aktualisasi diri, kemandirian, uji realita, tanggung jawab sosial, pemecahan masalah, optimisme dan kegembiraan, fleksibilitas pikiran, toleransi stres, yang dapat dikembangkan melalui kegiatan-kegiatan dalam Penjas Harmoni seperti yang telah disebutkan di atas..

\section{METODE}

Variabel bebas dalam penelitian ini berupa pemberian pelajaran Pendidikan Jasmani Harmoni. Variabel terikatnya adalah kecerdasan emosi.

Materi Penjas Harmoni merupakan kombinasi dari gerakan dasar olahraga, permainan, dan tari, melatih lima dasar kecerdasan emosi menurut Bar-On, yaitu kecakapan intrapersonal, kecakapan interpersonal, penyesuaian diri, manajemen stres, dan suasana hati umum. Perlakuan diberikan selama 14 pertemuan, seminggu sekali @ 70 menit. Kecerdasan emosi dalam penelitian ini diukur dengan Skala Perasaan, berisi 56 butir pernyataan, yaitu modifikasi dari Bar-On EQ inventory yang sudah disesuaikan untuk siswa SD. Pengukuran dilakukan sebelum dan sesudah perlakuan.

Subjek penelitian ini adalah siswa-siswa kelas V Sekolah Dasar, dengan pertimbangan mereka sudah cukup mengerti aturan-aturan permainan, sudah dapat lebih mengerti pernyataan yang tertulis dalam Skala Perasaan, alat ukur dalam penelitian ini. Adapun SD - SD yang terpilih (secara undian) beserta jumlah siswanya dapat dilihat pada Tabel 1.

Alat-alat yang dipergunakan dalam penelitian ini, yaitu: untuk kelompok intervensi, kaset atau CD untuk mengiringi tari Saman., tikar untuk alas menari, buku Pegangan Guru untuk Pendidikan Jasmani Harmoni dan jadwal'. Kemudian juga alat-alat olahraga yaitu bola sepak, bola basket, bola tenis, dan net. botol-botol Fanta 1,5 1, bendera-bendera ukuran $20 \times 30 \mathrm{~cm}$ dan tangkai sepanjang $60 \mathrm{~cm}$, serta tempat untuk menegakkan bendera. kartu-kartu berukuran $5 \times 10 \mathrm{~cm}$ bertuliskan jenis-jenis perasaan, balok titian atau titian bambu, kursi dan meja, Untuk kelompok kontrol, alat-alat olahraga yang biasa dipakai untuk penjas.

Alat-alat yang dipergunakan dalam penelitian ini, yaitu: untuk kelompok intervensi, kaset atau CD untuk mengiringi tari Saman., tikar untuk alas menari, buku Pegangan Guru untuk Pendidikan Jasmani Harmoni dan jadwal'. Kemudian juga alat-alat olahraga yaitu bola sepak, bola basket, bola tenis, dan net. botol-botol Fanta 1,5 1, bendera-bendera ukuran 
20 x $30 \mathrm{~cm}$ dan tangkai sepanjang $60 \mathrm{~cm}$, serta tempat untuk menegakkan bendera. kartu-kartu berukuran $5 \times 10 \mathrm{~cm}$ bertuliskan jenis-jenis perasaan, balok titian atau titian bambu, kursi dan meja, Untuk kelompok kontrol, alat-alat olahraga yang biasa dipakai untuk penjas.

Pretes untuk ke enam SD diadakan pada bulan Agustus 2007. Koordinasi dengan guruguru penjas dari SD-SD kelompok eksperimen diadakan beberapa hari sebelum pre tes, dan tidak dapat serentak karena sulit mendapatkan waktu untuk bertemu bagi guru-guru dari ketiga SD tersebut. Postes dilakukan pada bulan
November 2007. Penelitian ini juga terhenti di tengah oleh libur Puasa dan Idul Fitri. Agar mencapai 14 kali pertemuan, intervensi pernah dibuat 2 kali seminggu, pada jam olahraga dan jam pelajaran Kerajinan Tangan dan Kesenian.

\section{HASIL DAN PEMBAHASAN}

Analisis Data yang digunakan untuk menguji pengaruh perlakuan (Penjas Harmoni \& Penjas Reguler), tingkat akreditasi (A, B, C), dan jenis kelamin terhadap peningkatan kecerdasan emosi adalah ANOVA tiga jalur, dengan hasil seperti tampak pada Tabel 2.

Tabel 1. Kelompok Penelitian, Nama SD, dan Jumlah Siswa

\begin{tabular}{|c|c|c|c|}
\hline Tingkat Akreditasi & $\begin{array}{c}\text { Kelompok Eksperimen } \\
\text { Siswa Kls V }\end{array}$ & $\begin{array}{l}\text { Kelompok Kontrol } \\
\text { Siswa Kls V }\end{array}$ & Jumlah \\
\hline SDN Akr. A & $\begin{array}{l}\text { Bendan Ngisor } 01 \\
\quad 34 \text { siswa }\end{array}$ & $\begin{array}{l}\text { Pleburan } 04 . \\
36 \text { siswa }\end{array}$ & 70 siswa \\
\hline SDN Akr. B & $\begin{array}{l}\text { Jomblang } 04 \\
32 \text { siswa }\end{array}$ & $\begin{array}{l}\text { Pleburan } 01 \\
38 \text { siswa }\end{array}$ & 70 siswa \\
\hline SDN Akr. C & $\begin{array}{c}\text { Jomblang } 08,09 . \\
28 \text { siswa } \\
\end{array}$ & $\begin{array}{c}\text { Plalangan } 01 \\
33 \text { siswa } \\
\end{array}$ & 61 siswa \\
\hline Total & 94 & 107 & 201 \\
\hline
\end{tabular}

Tabel 2. Hasil Uji Anova

\begin{tabular}{lrrrrl}
\hline Sumber Variansi & \multicolumn{1}{c}{ JK } & dk & \multicolumn{1}{c}{ JKT } & \multicolumn{1}{c}{ F } & Sig. \\
\hline Perlakuan (KE/KK) & 27148,780 & 1 & 27148,780 & 318,254 & 0,000 \\
Tingkat Akreditasi & 144,047 & 2 & 72,023 & 0,844 & 0,431 \\
Jenis Kelamin & 65,719 & 1 & 65,719 & 0,770 & 0,381 Perlakuan * \\
Tingkat Akreditasi & 1159,310 & 2 & 579,655 & 6,795 & 0,001 \\
Perlakuan * Jen Kel & 22,833 & 1 & 22,833 & 0,268 & 0,606 \\
T.Akreditasi* Jenkel & 109,464 & 2 & 54,732 & 0,642 & 0,528 \\
Perlakuan* T.Akred* & & & & & \\
\hline Jenkel & 13,511 & 2 & 6,756 & 0,079 & 0,924 \\
\hline Adjused Squared & 0,629 & & & &
\end{tabular}

Adjusted $R$ Squared $=0,629$

Tabel 3. Perbandingan Mean Peningkatan Kecerdasan Emosi Ditinjau dari Jenis Perlakuan \& Tingkat Akreditasi Sekolah

\begin{tabular}{lcccc}
\hline Perlakuan & Akreditasi & Mean & \multicolumn{2}{c}{ Taraf Kepercayaan 95\% } \\
\cline { 3 - 5 } & & & Batas bawah & Batas atas \\
\hline Intervensi & $\mathrm{A}$ & 25,258 & 22,112 & 28,404 \\
& $\mathrm{~B}$ & 21,340 & 18,061 & 24,619 \\
& $\mathrm{C}$ & 18,292 & 14,813 & 21,770 \\
\hline
\end{tabular}


Kelompok perlakuan (Kelompok intervensi dan kelompok kontrol) mempunyai nilai $\mathrm{F}$ sebesar 318,254, dengan $\mathrm{p}=0,000(\mathrm{p}<0,01)$. Ini berarti terdapat perbedaan yang sangat signifikan pada peningkatan kecerdasan emosi antara kelompok eksperimen dengan kelompok kontrol. Mean total kelompok eksperimen $(21,90)>$ mean total kelompok kontrol(-1,92). Dengan demikian dapat dikatakan bahwa 'Pendidikan Jasmani Harmoni efektif meningkatkan kecerdasan emosi siswa SD'.

Sebagai materi yang dirancang untuk meningkatkan kecerdasan emosi, dalam hal ini siswa SD, Pendidikan Jasmani Harmoni dapat berhasil. Hal ini konsisten dengan hasil penelitian Ulutas dan Omeroglu (2007) yang menunjukkan bahwa kecerdasan emosi akan berkembang oleh pendidikan yang berfokus pada keinginan membentuk anak mengembangkan kecerdasan emosi dasar, seperti mengekspresikan, memahami, dan mengelola emosi, serta menggunakan kemampuan untuk menghadapi permasalahan kehidupan sehari-hari.

Tingkat Akreditasi (akreditasi A, B, C) memberi nilai $\mathrm{F}$ sebesar 0,844 , dengan $\mathrm{p}=$ $0,431(p>0,05)$. Ini berarti tidak ada perbedaan yang signifikan pada kenaikan kecerdasan emosi antara kelompok akreditasi A, B, maupun C.

Jenis kelamin (laki-laki dan perempuan) memberi nilai $\mathrm{F}=0,770$ dengan $\mathrm{p}=0,381(\mathrm{p}>$ $0,05)$. Ini berarti tak ada perbedaan yang signifikan pada kenaikan kecerdasan emosi antara siswa laki-laki dan perempuan. Interaksi antara perlakuan dan tingkat akreditasi sekolah memberi nilai $F$ sebesar 6,795 dengan $p=$ $0,001$ ( $p<0,01)$. Ini berarti bahwa terdapat pengaruh bersama antara perlakuan dengan tingkat akreditasi sekolah terhadap peningkatan kecerdasan emosi.

Interaksi antara perlakuan dengan jenis kelamin memberi nilai $\mathrm{F}$ sebesar 0,268 dengan $p=0,606(p>0,05)$. Ini berarti tak ada pengaruh bersama antara perlakuan dan jenis kelamin. Interaksi antara tingkat akreditasi sekolah dengan jenis kelamin memberi nilai $\mathrm{F}$ sebesar 0,642 dengan $p=0,528(p>0,05)$. Ini berarti tidak ada pengaruh bersama antara tingkat akreditasi sekolah dengan jenis kelamin. Interaksi antara perlakuan, tingkat akreditasi sekolah, dan jenis kelamin memberi nilai $\mathrm{F}$ sebesar 0,079 dengan $p=0,924(p>0,05)$. Ini berarti tidak ada pengaruh bersama pada peningkatan kecerdasan emosi antara perlakuan, tingkat akreditasi sekolah, dan jenis kelamin.

Hasil nomor 2 menunjukkan bahwa tidak ada perbedaan yang signifikan pada peningkatan kecerdasan emosi antara sekolah yang terakreditasi A, B, maupun C. Namun hasil nomor 4 menunjukkan bahwa ada pengaruh bersama antara perlakuan dengan tingkat akreditasi sekolah. Jadi, peningkatan kecerdasan emosi pada kelompok intervensi bukan sematamata dipengaruhi oleh intervensi tetapi juga dipengaruhi oleh tingkat akreditasi. Perbedaan antar tingkat akreditasi akan dapat dilihat lebih jelas bila analisis diteruskan dengan pairwise comparison, yang khusus membandingkan mean peningkatan kecerdasan emosi, antara yang ditinjau dari jenis perlakuan dengan yang ditinjau dari tingkat akreditasi sekolah. Hasil analisis dengan pairwise comparison adalah sebagai berikut.

Kelompok kontrol tidak disajikan dalam tabel ini karena tidak ada peningkatan. Pada kelompok eksperimen, mean peningkatan kecerdasan emosi dari siswa SD terakreditasi A adalah 25, 258, yaitu di antara 22,112 - 28,404. Mean peningkatan kecerdasan emosi siswa SD terakreditasi B adalah 21,340, yaitu berada diantara 18,061- 24,619. Angka ini berada di luar rentangan 22,112 - 28,404. Ini berarti ada perbedaan peningkatan kecerdasan emosi antara SD Terakreditasi A dengan SD Terakreditasi B. Mean peningkatan kecerdasan emosi SD Terakreditasi C adalah 18,292, yaitu di antara 14,813-21,770. Mean ini juga berada di antara 18,061 - 24,619 seperti halnya SD Terakreditasi B. Ini menunjukkan bahwa tidak ada perbedaan peningkatan kecerdasan emosi antara SD Terakreditasi B dengan SD Terakreditasi C. Namun mean 18,292 berada di luar rentangan 22,112 - 28,404. Jadi ada per- 
bedaan peningkatan kecerdasan emosi antara SD Terakreditasi A dengn SD Terakreditasi C.

Perbedaan ini dapat dihubungkan dengan fakta bahwa frekuensi kehadiran guru wali pada ketiga SD tersebut berbeda. Kehadiran guru wali untuk SDN Bendan Ngisor 01 (Akreditasi A) pada pertemuan- pertemuan intervensi paling banyak, yaitu $92 \%$, kemudian guru wali pada SDN Jomblang 04 (Akreditasi B) 67\% dan frekuensi kehadiran guru wali SDN Jomblang 8, 9 (Akreditasi C) paling kurang, yaitu17\%. Jadi perbedaan ini bukan karena perbedaan tingkat akreditasi, tetapi mungkin karena perbedaan kehadiran (partisipasi guru). Mengenai korelasi antara partisipasi guru dan perolehan hasil belajar, ini sesuai dengan hasil penelitian Solmon dan Lee (1997).

Keikutsertaan guru wali disamping guru penjas atau guru tari pada setiap pertemuan membuat siswa lebih senang, karena ketika dapat menguasai suatu gerakan atau kecakapan disaksikan oleh guru penjas maupun guru wali. Kesenangan ini membuat siswa bersemangat untuk mengikuti intervensi. Ini sesuai dengan hasil penelitian Reeve (Chen, 1996). Dalam intervensi ini guru tari atau guru penjas yang hadir bermakna bagi siswa sebagai orang dewasa yang lebih berpengalaman yang membantu mendapatkan suatu kecakapan. Ini sesuai dengan prinsip konstruktivisme dari Vygotsky (Elkind, 2004) dalam konsep ZPD (Zone Proximal Development), tetapi kehadiran guru wali hanya sebagai individu yang memberi semangat atau membangkitkan self efficacy siswa (Bandura, 1997)

Dengan demikian hasil yang diharapkan, yaitu peningkatan kecerdasan emosi sebagai sasaran belajar dapat tercapai. Keadaan bersemangat dari siswa yang membuat pelajaran penjas menjadi menarik, sehingga siswa dapat belajar lebih baik, adalah sesuai dengan pendapat Krappet et. al. (Chen, 1996). Pengalaman dalam bekerjasama dengan teman, menyesuaikan gerak dengan teman dalam tari, menahan diri untuk tidak memonopoli bola dalam permainan bola panas, misalnya, karena akan dimarahi teman atau ditegur guru, merupakan pengalaman sosial. Pengalaman sosial dalam penjas membuat penjas itu berarti bagi siswa, sehingga siswa tertarik dan dapat belajar lebih baik. Ini sesuai dengan temuan Weiss dan Duncan (1992) dan Kenyon (Chen, 1996).

Selanjutnya untuk menguji pengaruh perlakuan (Penjas Harmoni) terhadap peningkatan tiap komponen kecerdasan emosi digunakan Manova satu jalur. Hasilnya menunjukkan halhal sebagai nberikut: 1) Peningkatan kecakapan intrapersonal kelompok Penjas Harmoni lebih tinggi dari kelompok kontrol (mean 8,6>0,19; $\mathrm{p}<0,01)$ 2) Peningkatan kecakapan interpersonal kelompok Penjas Harmoni lebih tinggi dari kelompok kontrol (mean 5,80>0,38; $\mathrm{p}<0,01$ ). 3) Peningkatan kecakapan penyesuaian diri kelompok Penjas Harmoni lebih tinggi dari kelompok kontrol (mean 3,84>0,96; p<0,01). 4) Peningkatan kecakapan manajemen stres kelompok Penjas Harmoni lebih tinggi dari kelompok kontrol (mean 2,94>0,68; $\mathrm{p}<0,01$ ). 5) Peningkatan suasana hati umum kelompok Penjas Harmoni lebih tinggi dari kelompok kontrol (mean 2,79>0,07; $p<0,01$ ).

Akhirnya untuk menguji apakah ada perbedaan kecerdasan emosi secara keseluruhan antara siswa laki-laki dan perempuan digunakan uji statistik Anova satu jalur. Hasilnya menunjukkan, tidak ada perbedaan kecerdasan emosi antara siswa laki-laki dan perempuan.

\section{PENUTUP}

Berdasarkan hasil penelitian ini dapat disimpulkan hal-hal sebagai berikut.

- Pengajaran Penjas Harmoni efektif meningkatkan kecerdasan emosi siswa-siswa SD.

- Pengajaran penjas Harmoni efektif meningkatkan kecakapan-kecakapan intrpersonal, interpersonal, penyesuaian diri, manajemen stres, suasana hati.

- Tidak ada pengaruh jenis kelamin terhadap peningkatan kecerdasan emosi.

- Tidak ada pengaruh tingkat akreditasi sekolah terhadap peningkatan kecerdasan emosi.

- Ada pengaruh bersama antara tingkat akreditasi sekolah dengan perlakuan terhadap peningkatan kecerdasan emosi. 
- Tidak ada perbedaan kecerdasan emosi antara siswa laki-laki dan perempuan.

\section{SARAN}

- Guru-guru Pendidikan Jasmani: guru dapat memakai model Pendidikan Jasmani Harmoni untuk memperkaya materi pengajaran, disesuaikan dengan KTSP 2006. Karena tidak ada perbedaan kecerdasan emosi antara siswa laki-laki dan perempuan maka semua kegiatan dalam Penjas Harmoni dapat dilakukan siswa perempuan maupun lakilaki. Sebagai catatan, kelompok tari Saman hanya terdiri dari siswa laki-laki saja atau perempuan saja. Hal yang tidak boleh dilupakan adalah, guru penjas harus selalu berusaha mengembangkan iklim motivasional dalam mengajar, agar siswa semakin menyukai penjas.

- Pejabat Pengambil Kebijakan: pejabat Kantor Dinas Pendidikan Kota Semarang agar dapat merekomendasi penggunaan model Penjas Harmoni untuk melengkapi KTSP 2006.

- Peneliti yang akan datang: mencari permainan dan juga tarian bersama tradisional yang lain yang diperkirakan dapat meningkatkan kecerdasan emosi.

\section{UCAPAN TERIMA KASIH}

Peneliti mengucapkan terima kasih kepada Direktur DP2M, Dirjen Dikti Kemendiknas RI yang telah memberikan kesempatan dan dana Penelitian Hibah Bersaing 2007 dan biaya untuk menghadiri $26^{\text {th }}$ ACHPER International Conference di Brisbane, Australia, pada tanggal 8 - 10 Juli 2009. Juga Dewan Redaksi dan Staf Jurnal Cakrawala Pendidikan yang telah memberi kesempatan terpublikasinya hasil penelitian ini.

\section{DAFTAR PUSTAKA}

Azzarito, L \&\& Ennis, CD. 2003. "A Sense of Connection, towards Social Construc- tivist Physical Educaton". Sport, Education and Society, 8 (2), 179-198.

Bandura, A. 1997. Self-Efficacy: The Exercise of Control. N.York: W.H. Freeman and Company.

Bandura,A. 2002. "Social Cognitive Theory in Cultural Contex"t. Journal of Applied Psychology: An International Review, 51, 269-290.

Bar-On, R. 1997. "Development of the Bar-On EQ-i: A Measure of Emotional and Social Intelligence". Paper presented at the 105 th annual convention of the American Psychological Association in Chicago Toronto: Multi-Health Systems Inc.

Binder, D. 1995. Fair Play for Kids. A Handbook of Activities for Teaching Fair Play. Gloucester Canada: Fair play Canada.

Bucher, C.A.,\& Thaxton, N.A. 1979. Physical Education for Children. New York: McMillan Publishing Co., Inc.

Chen, A. 1996. Student Interest in Activities in a Secondary Physical Education Curriculum: An Analysis of Student Subjectivity. Research Quarterly for Exercise and Sport, 67 (4), 424-432.

Crum, B. 2003. "Task and Competencies of Physical Education Teachers: Consequences for PETE Programs". Paper. International Conference on Sport Sciences and Physical Education Profession. Bandung, March

Elkind, D. 2004. "Vygotsky's Educational Theory in Cultural Context". Bulletin of The Meninger Clinic. New York 68 (4), 352-353. http://proquest.umi.com/pqdweb. Accessed 28/07/2009.

Goleman, D. 2001. Kecerdasan Emosional untuk Mencapai Puncak Prestasi (Terj. 
Widodo, ATK), Cetakan ke 4. Jakarta: PT. Gramedia.

Gottman, J.,and De Claire, J. 1998. Kiat-kiat Membesarkan Anak Yang Memiliki Kecerdasan Emosional (Terj. Widodo, ATK). Jakarta : PT. Gramedia.

Hein, S., 2006 ). Introduction to Emotional Intelligence. Wayne Payne's 1985 Doctoral Paper on Emotions \& Emotional Intelligence. http:/eqi.org/sph test 1.htm. accessed 02/02/2006.

Hidayat, R. 2005. Menerobos Pembelajaran Tari Pendidikan. Malang: Banjar Seni Gantar Gumelar.

Hurlock, E.B. 1999. Psikologi Perkembangan. Terjemahan Istiwidayanti \& Soedjarwo. Ed. V. Jakarta: Penerbit Erlangga.

Ibrahim, R. 2001. Landasan Psikologis Pendidikan Jasmani di Sekolah Dasar. Jakarta: Ditjen Olahraga. DEPDIKNAS.

Ina, S.D. 2002. "Tari Pendidikan". Makalah Seminar dan Diskusi Tari Pendidikan, Indonesia Dance Festival 2002. Jakarta: Graha Bakti Budaya, 21 Sept.

Kelly, B., Longbottom, J., Potts, F., \& Williamson, J. 2004. "Applying Emotional Intelligence: Exploring the Promoting Alternative Thinking Strategies Curriculum". Educational Psychology in Practice. 20(3), 221-240.

Kompas, Harian, 2006. Jangan Dramatisasi Pengadilan Raju. Medan 2 Maret, h. 3. kol 1-3.

Lawrence, D.,\& Hope, B. 2007. Circuit Training. $2^{\text {nd }}$ ed. London: A\&C Black Publishers.

Lee, A.M., Landin, D.K., \& Carter, J.A. 1992. "Student Thoughts during Tennis Instruction". Journal in Teaching Physical Education. 11, 256-267.
Lopez, P.N., Salovey, P., \& Straus, R. 2003. "Emotional Intelligence, Personality, and the Perceived Quality of Social Relationships". Personality and Individual Differences 35. ,641-658.

Lutan, R. 2004. Pembaruan Pendidikan Jasmani di Indonesia. Jakarta: Penerbit Ditjen Olahraga.

Mahendra, A. 2006. "Penjas Berbasis masalah Gerak" makalah Lokakarya Pembelajaran Pendidikan Jasmani. Bandung: 24 26 Juli.

Nopembri, S. 2004. "Pembelajaran Terpadu Mata Pelajaran Pendidikan Jasmani di Sekolah Dasar". Jurnal Pendidikan Jasmani Indonesia. 1. (1) $15-26$.

Ommundsen, Y., \& Bar-Eli, M. 1999. "Psychological Outcomes in Physical Education", dalam Y.V. Auweele, et al. (Eds). Psychology for Physical Educators. USA : Human Kinetics.

Petrides, K.V., Sangareau,Y., Furnham, A., Frederickson, N. 2006. Traits, Emotional Intelligence, and Children's Peer Relations at School. Social Development, 15, 537-547.

Poerwanti, E. 2005. Memahami Pertumbuhan Kecerdasan Intelektual dan Kecerdasan Emosional Anak untuk Kepentingan Pendidikan. www.malang.ac.id/jurnal/fip/sd/-8k. Diakses 02/02/2006.

.Salovey, P., and Sluyter, D.J. 1997. Emotional Development and Emotional Intelligence: Educational Implications. New York: Basic Books.

Shapiro, L.E. 2003. How to raise a child with a high E.Q. Terj.Widodo. A T.K. Cet. Keenam. Jakarta: PT Gramedia.

Solmon, M. A., and Lee, A. M. 1997. "Development of an Instrument to Asses Cognitive Processes in Physical Education 
Classes". Research Quarterly for Exercise and Sport. 68 (2), 152-160

Strongman, K.T. 2003. The Psychology of Emotion. $5^{\text {th }}$ ed. Chichester, West Sussex, England: John Wiley \& Sons Ltd.

Triana, D.D. 2005. "Meningkatkan Kreativitas dalam Pembelajaran Tari Melalui Metode Proses pada Anak Pra Sekolah". Harmonia. VI (1), 39-46.
Ulutas, I. \& Omeroglu, E. 2007. “The effect of Emotional Intelligence Education Program on Emotional Intelligence of Children". Social Behavior and Personality. 35(10), 1365-1372.

Weiss, M.R., Duncan, S.C. 1992. "The Relationships between Physical Competence and Peer Acceptance in the Context of Children Sport Participation". Journal of Sport and Exercise Psychology, 14, 177191. 